\title{
Balneotherapeutic effects of high mineral spring water on the atopic dermatitis-like inflammation in hairless mice via immunomodulation and redox balance
}

Johny Bajgai ${ }^{1,2}$, Ailyn Fadriquela1,2, Jesmin Ara ${ }^{1,2}$, Rahima Begum,2, Md Faruk Ahmed ${ }^{1,2}$, Cheol-Su Kim³, Soo-Ki Kim ${ }^{3}$, Kwang-Yong Shim ${ }^{4^{*}+}$ and Kyu-Jae Lee ${ }^{1,5^{*+}}$

\begin{abstract}
Background: Atopic dermatitis (AD) is a chronic relapsing allergic inflammatory skin disease that currently affects millions of children and adults worldwide. Drugs used to treat these inflammatory diseases include anti-histamines, corticosteroids and calcineurin inhibitors but these drugs have their limitations such as adverse effects with their long-term usage. Thus, researcher's interest in several alternative and complementary therapies are continually growing and balneotherapy is one of these approaches. Therefore, we investigate the bathing effect of high concentration mineral spring water (HMW) on redox balance and immune modulation in 2,4-dinitrochlorobenzene (DNCB)-induced atopic dermatitis like inflammation in hairless mice.

Methods: We induced AD-like inflammation by application of DNCB on the dorsal skin of female skh-1 hairless mice. The mice were treated with 100\% pure HMW (PHMW) and 10\% diluted HMW (DHMW) through bathing once a day for 4 weeks. Tacrolimus ointment $(0.1 \%)$ was used as positive control (PC) and only DNCB treatment as negative control $(\mathrm{NeC})$ group. The severity of skin lesion inflammation was assessed through clinical scoring and observing scratching behavior. Levels of immunoglobulin $\mathrm{E}(\mathrm{lgE})$ and inflammatory cytokines in serum were detected by ELISA and multiplex bead array system, and the levels of oxidative stress-related biomarkers and antioxidant enzyme were also measured.

Results: We found that HMW significantly decreased the scratching behavior in PHMW and DHMW groups at the 2nd week and in PHMW group at 4th week compared to NeC group. Likewise, serum IgE level was significantly decreased in DHMW group as compared to NeC group. In line, the level of inflammatory cytokines in serum such as interleukin (IL)-1 $\beta, I L-13$ and tumor necrosis factor-a were significantly inhibited in PHMW and DHMW groups compared to NeC group. In parallel, total reactive oxygen species (ROS) of serum level was significantly decreased in PHMW treatment groups compared to NeC group. Consistently, serum malondialdehyde (MDA) level in PHMW group was lower than in NeC group. By contrast, glutathione peroxidase (GPx) activity was significantly enhanced in PHMW than NeC.
\end{abstract}

Conclusion: Collectively, our study indicates a balneotherapeutic effect of HMW on DNCB-induced AD like inflammation in hairless mice via immunomodulation and redox balance.

Keywords: Atopic dermatitis, Balneotherapy, High mineral spring water, Immunomodulation, Redox balance

\footnotetext{
*Correspondence: kyshim@yonsei.ac.kr; medbio9@gmail.com

${ }^{\dagger}$ Equal contributors

${ }^{4}$ Department of Internal Medicine, Wonju College of Medicine, Yonsei University, Wonju, Gangwon 26426, Republic of Korea

'Department of Environmental Medical Biology, Wonju College of Medicine,

Yonsei University, Wonju, Gangwon 26426, Republic of Korea

Full list of author information is available at the end of the article
} 


\section{Background}

Atopic dermatitis (AD) is a chronic relapsing allergic inflammatory skin disease, and currently affects millions of children and adults worldwide with its prevalence increasing two to three times over the past three decades $[1,2]$. Although the exact etiology of AD has not been completely elucidated, a variety of causal factors including environmental, psychological, pharmacological [3], immunological and genetic [4] have been reported. In the therapeutic point of view, AD is featured by an impairment of the skin-barrier function, increased oxidative stress, dysfunctional immune system and elevated serum immunoglobulin E (IgE) levels [1, 3]. To alleviate these pathognomic feature, conventional drugs like antihistamines, corticosteroids, and calcineurin inhibitors have been used to treat these inflammatory allergic disorders. However, these drugs have their own limitations, such as the short term usage (2-4 weeks), which is insufficient for clinical effectiveness, adverse side effects, and intolerance. For instance, long-term usage of these drugs is known to suppress the hypothalamic-pituitary-adrenal axis and related sequelae $[5,6]$. To overcome this, clinicians' interests in the alternative and complementary therapies are continually growing. Balneotherapy is one of these candidates to ameliorate $\mathrm{AD}$ with or without conventional medication.

Bathing in spring water (balneotherapy) has been widely used as a therapeutic tool for the treatment of skin diseases like acne, AD and psoriasis, and is prescribed by some European countries around the world [7-9]. Balneotherapy uses mineral water that is originates from different natural springs, and according to their location may be low mineralized (0.6-2 mg/L), mildly mineralized $(>2-10 \mathrm{mg} / \mathrm{L})$ or highly mineralized $(>10 \mathrm{mg} / \mathrm{L})$ water $[10,11]$. Cumulative studies have hinted that the application of minerals like sulphur [12], manganese [13], magnesium [14], zinc [15], selenium and strontium [16] might exert gross therapeutic effects on skin diseases in human and DNCB-induced AD like inflammation in hairless mice. Another mechanistic evidence suggested that body exposure to mineral water at the spa would beneficially affect the immune system and antioxidant mechanism $[17,18]$. Of these, a report in Japan showed the therapeutic effect of balneotherapy on AD [18]. Apart from this, the moderate level of some minerals such as manganese and sulfur in thermal spring water have been reported to be bactericidal against Staphylococcus aureus (SA) commensally resident in AD patient's skin $[13,19]$. Despite of these intermittent and superficial evidence of balneotherapy against AD, balneotherapy with higher levels of complex minerals (magnesium, calcium, chlorine, manganese, sulphur and strontium) in spring water is poorly documented, and further unclear about the detailed mechanisms of immunomodulation and redox balance in $\mathrm{AD}$ like inflammation. To address this issue, using natural mineral spring water, which is known for higher levels of complex minerals (Table 1), we investigated the balneotherapeutic effects on immunomodulation and redox balance in 2,4dinitrochlorobenzene (DNCB)-induced atopic dermatitis like inflammation in hairless mice.

\section{Methods}

\section{Experimental animals}

Five-week-old female SKH-1 hairless mice with the mean weight (mean \pm SD) $25 \pm 4.2$ g were purchased from Orient Bio Inc. (Seongnam, Republic of Korea) and used in carrying out the studies. The mice were obtained at the small unit of animal care and use department in Wonju College of Medicine, Yonsei University, Republic of Korea.

\section{Housing and husbandry}

Handling of mice was done in accordance with the use and care protocols of Institutional Animal Care and Committee (IACUC) at Wonju College of Medicine, Yonsei University, Republic of Korea. The mice were kept in spacious plastic cages $(390 \times 275 \times 175 \mathrm{~mm})$ with wood shaving bedding and identified by labeling with surgical skin markers marking at the tail. They were acclimatized for 7 days to the housing environment prior

Table 1 Hydrochemical analysis of high mineral spring water

\begin{tabular}{|c|c|c|}
\hline Mineral Content & Standard (mg/L) & $\mathrm{HMW}(\mathrm{mg} / \mathrm{L})$ \\
\hline Potassium $\left(\mathrm{K}^{+}\right)$ & 5 & 9.84 \\
\hline Magnesium $\left(\mathrm{Mg}^{2+}\right)$ & 25 & 183 \\
\hline Calcium $\left(\mathrm{Ca}^{2+}\right)$ & $5-500$ & 2820 \\
\hline Sodium $\left(\mathrm{Na}^{+}\right)$ & 200 & 2900 \\
\hline Chlorine $\left(\mathrm{Cl}^{-}\right)$ & 250 & 9660 \\
\hline Sulphate $\left(\mathrm{SO}_{4}^{2-}\right)$ & 250 & 1000 \\
\hline Lithium (Li) & 0.02 & 14.1 \\
\hline Strontium (Sr) & 0.46 & 91.6 \\
\hline Manganese (Mn) & 0.3 & 21.0 \\
\hline Lead (Pb) & 0.05 & 0.05 \\
\hline Zinc (Zn) & 1.0 & 0.03 \\
\hline silicon dioxide $\left(\mathrm{SiO}_{2}\right)$ & $1-30$ & 11.8 \\
\hline Iron (Fe) & 0.3 & 0.02 \\
\hline Copper (Cu) & 0.003 & 0.03 \\
\hline Fluoride $\left(F^{-}\right)$ & 1.5 & 0.52 \\
\hline $\mathrm{pH}$ & & 7.53 \\
\hline Total dissolved solids & 500 & 17,766 \\
\hline
\end{tabular}

The above analysis is performed by using the inductively coupled Plasma-Mass Spectrometer (ICP-MS) and a Thermo Scientific iCAP 6500 duo Inductively Coupled Plasma-Atomic Emission Spectrometer (ICP-AES) by Korea Institute of Geosciences and Mineral Resources (Daejeon, Republic of Korea). HMW High mineral spring water 
to treatment and were maintained in a controlled environment with atemperature of $22 \pm 2{ }^{\circ} \mathrm{C}$ and $40-60 \%$ humidity under a 12:12-h light-dark cycle. Standard rodent chow food (5 L79, PMI Nutrition', LAND O'LAKES, INC, Minnesota, USA) and primary filtered water were supplied free to access until the end of the experiment. At the start of the experiment, 50 mice were randomized into five groups, five mice each cage $(n=10$ respectively) as follows: Normal control group (NC), Negative control group $(\mathrm{NeC})$ treated with $\mathrm{DNCB}$ only $+\mathrm{DW}$ bathing, Positive control group (PC) treated with DNCB $+0.1 \%$ tacrolimus ointment + DW bathing, $100 \%$ pure high concentration mineral water (PHMW) group treated with $\mathrm{DNCB}+\mathrm{PHMW}$ bathing, and 10\% diluted high concentration mineral water (DHMW) group treated with DNCB + DHMW bathing. The study protocol of the experiment was approved by the Institutional Animal Care and Use Committee (IACUC) at Wonju campus, (Ethical approval no: YWC-160513-1) Yonsei University, Gangwon, Wonju, and Republic of Korea. All the experiments were conducted between 7 a.m. and 6 p.m. to minimize the effects of environmental changes.

\section{Preparation of experimental water}

A colorless clear solution of natural high mineral spring water (HMW) was supplied from Tae chang Co.Ltd. (Gyeokpo, Buan-gun, Republic of Korea). Mineral compositions of HMW were analyzed by a Thermo Electron $x$ Series Inductively Coupled Plasma-Mass Spectrometer (ICP-MS) and a Thermo Scientific iCAP 6500 duo Inductively Coupled Plasma-Atomic Emission Spectrometer (ICP-AES) in Korea Institute of Geosciences and Mineral Resources (Daejeon, Republic of Korea) and the result was as Table 1 . All the experimental water were stored in the big plastic container covered with a lid at $4{ }^{\circ} \mathrm{C}$ to protect from light and humidity until use. DHMW was prepared by $10 \%$ dilution of PHMW. For the treatment of $\mathrm{NeC}$ and $\mathrm{PC}$ groups, distilled water (DW) was used.

\section{Induction of allergic dermatitis with DNCB in skh-1 hair- less mice}

AD-like inflammatory skin lesions were induced in skh1 hairless mice by sensitization with $200 \mu \mathrm{L} /$ mouse/day $1 \%$ DNCB (dissolved in a 3:1 mixture of acetone and olive oil) for 1 week, and boosted with $150 \mu \mathrm{L} /$ mouse of $0.5 \%$ DNCB every alternate day for 3 weeks according to previous established methods [20]. The 3 weeks of boosting and bathing was followed by one more week of bathing with sample waters only. DNCB solutions were topically applied to dorsal skin (approximately $4 \mathrm{~cm}^{2}$ ) on each mouse except NC mice. In intact PC mice, tacrolimus ointment (0.1\% ProtopicCo.Ltd. Osaka, Japan) was topically applied on the dorsal skin, seven times a week for 4 weeks (day 8-35). After a total of 4 weeks treatment, mice were anesthetized with isoflurane (Hana Pharm. Co., Hwaseong, Republic of Korea) in the mixture of $70 \% \mathrm{~N}_{2} \mathrm{O}$ and $28.5 \% \mathrm{O}_{2}$ to minimize suffering and distress and blood samples of all the mice were collected from retro-orbital veins in EDTA vacutainer tubes and kept in ice packs. Immediately after blood collection, mice were sacrificed by cervical dislocation. The collected blood sample was centrifuged for $5 \mathrm{~min}$ at $14000 \mathrm{rpm}$ and the separated serum was stored in $-80^{\circ}$ $\mathrm{C}$ before use. A time line diagram for this experiment is shown in (Fig. 1).

\section{Bathing method for treatment after induction of AD-like inflammation}

Five mice were freely bathed in a plastic cage $(390 \times 275 \times 175 \mathrm{~mm})$ containing $4 \mathrm{~cm}$ depth of PHMW, DHMW and DW respectively for $15 \mathrm{~min} /$ day for 4 weeks. The mice of both PHMW and DHMW groups were bathed in PHMW and DHMW, and PC and DNCB control group were bathed in DW to provide the same bathing condition. All the experimental water were warmed around $37^{\circ} \mathrm{C}$ before bathing.

\section{Evaluation of the skin severity}

The dermatitis severity was assessed by using skin scoring procedure, the frequency of scratching and skin test after triggering $\mathrm{AD}$ via $\mathrm{DNCB}$. The dermatitis skin scoring procedure assessed eczema area and a severity index scoring system applied as follows: 0 , no symptoms; 1 , mild symptom; 2 , moderate symptom; 3 , severe symptom. The overall dermatitis score was defined as the sum of scores for erythema, edema, excoriation and scaling/dryness. The skin scoring was assessed once a week during the 4 weeks of treatment. Simultaneously, scratching actions such as rubbing their dorsal skin with their hind paws, their nose and ears were counted on 2nd and 4th week within 15 min in triplicate observation.

\section{Measurement of total lgE}

Blood samples were collected from the retro-orbital plexus of mice at the end of the experiment. Serum was obtained by centrifugation at $14000 \mathrm{rpm}$ for $5 \mathrm{~min}$ and stored in $-80{ }^{\circ} \mathrm{C}$ until use. The serum total IgE levels were determined by using the mouse IgE ELISA kit (BD Biosciences, San Diego, CA, USA) according to manufacturer's manual instructions. The reaction product was measured calorimetrically at $450 \mathrm{~nm}$ with a microplate reader (BioTekInstrument, Winooski, VT, U.S.A).

\section{Measurement of cytokine concentration}

Inflammatory cytokines such as interleukin (IL)-1 $\beta$, IL13 and tumor necrosis factor-alpha (TNF- $\alpha$ ) were measured in serum by using multiplex array kit (Bio-Rad, 


\section{Experimental Schedule}

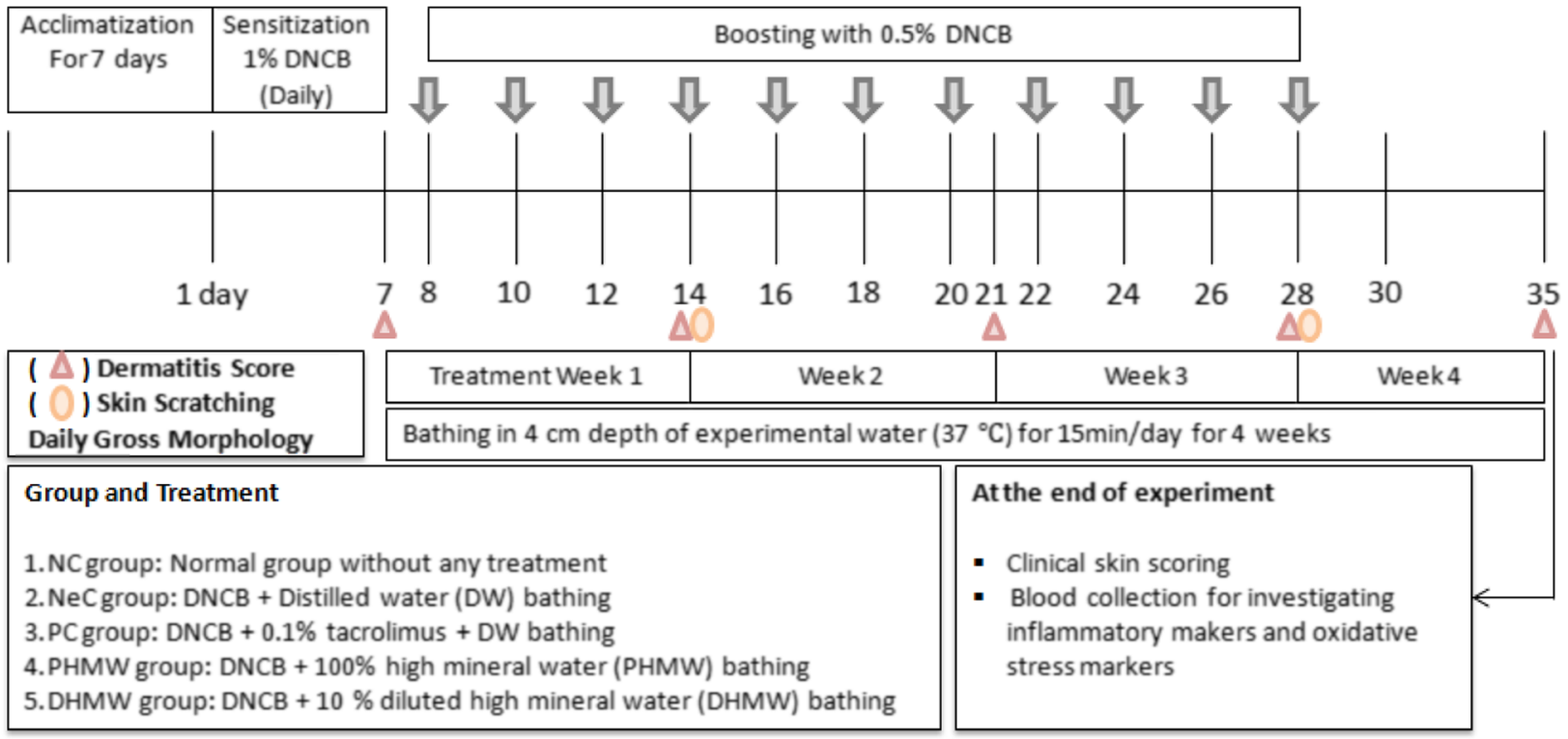

Fig. 1 Scheme of the experimental procedure. To induce AD-like inflammation 1\% DNCB was topically applied to the dorsal back skin of female skh-1 hairless mice for 1 week once a day and boosted with 0.5\% DNCB every alternate day for 3 weeks. After 3 weeks of boosting and bathing treatment, one more week of only bathing treatment was followed. Mice were either treated with Negative control group (NeC): only DNCB+ DW bathing, Positive control group (PC): DNCB +0.1\% tacrolimus ointment + DW bathing; 100\% pure high concentration mineral water (PHMW) group (PHMW): DNCB + PHMW bathing; 10\% diluted high concentration mineral water (DHMW) group (DHMW): DNCB + DHMW bathing. On day 35, mice were sacrificed and blood samples were collected for further analysis

San Diego, CA, U.S.A.) and run on Luminex technology (Bio-Plex Multiplex Bead array system TM, Bio-Rad Hercules, CA, U.S.A.) according to manufacturer's instruction. Raw fluorescence data were analyzed by software using a 5-parameter logistic method.

\section{Determination of total ROS}

The level of total ROS production in serum was assessed by measuring the oxidation of 2-4-dichlorodihydrofluorescein diacetate (DCFH-DA) (Abcam, Cambridge, MA, U.S.A) by following manufacturer's manual instructions. In brief, $50 \mu \mathrm{L}$ of samples were prepared in the 96-well plate. One hundred $\mu \mathrm{L}$ of $10 \mu \mathrm{M}$ DCFH-DA was added into each well and the plate was incubated for $30 \mathrm{~min}$ in the dark. Fluorescence at $488 \mathrm{~nm}$ excitation/525 nm emission was analyzed by using DTX- 880 multimode microplate reader (Beckman Coulter Inc., Fullerton, CA, U.S.A).

\section{Measurement of MDA}

The level of MDA, a marker of oxidative stressin serum was measured using thiobarbituric acid reactive substances (TBARS) assay kit (Cell Biolabs, Inc., San Diego, CA, U.S.A). The assay was performed according to manufacturer's instructions. The reaction product was measured calorimetrically at $532 \mathrm{~nm}$ with a microplate reader (Biotek instruments, Winooski, VT, U.S.A).

\section{Measurement of GPx}

GPx activity in serum was measured for $\mathrm{H}_{2} \mathrm{O}_{2}$ scavenging capacity by modified Cayman's GPx assay kit (Cayman Chemical Co., Ann Arbor, MI U.S.A) according to the instruction of the manufacturer. The oxidation of $\mathrm{NADPH}$ to $\mathrm{NAD}^{+}$was measured at the absorbance at $340 \mathrm{~nm}$ at least 3 times using automated micro plate reader (Beckman Coulter, Inc., Fullerton, CA, U.S.A) at one-minute interval.

\section{Experimental outcomes}

This study provides the in vivo bathing effect of HMW on immunomodulation and redox balance in DNCBinduced $\mathrm{AD}$ - like inflammation in hairless mice.

\section{Statistical analysis}

Data values were expressed as the mean \pm standard deviation (S.D). The mean values among groups were analyzed and compared using one-way ANOVA followed by subsequent multiple comparison tests (Tukey) with Prism version 5.0 software packages (Graph Pad Software Inc., 
U.S.A). Significant differences were considered statistically at ${ }^{*} p<0.05$, ** $p<0.01$ and ${ }^{* * * *} p<0.001$.

\section{Results \\ HMW bathing ameliorates DNCB-induced skin severity in hairless mice}

To investigate the bathing effects of PHMW and DHMW in DNCB- induced hairless mice, we evaluated skin severity through clinical skin scoring of eczema area, severity index and scratching tendency. The repetitive application of DNCB induced AD-like lesions involving severe skin symptoms in hairless mice. We found that PHMW and DHMW groups showed a slight decrease of DNCB-induced skin severity compared to $\mathrm{NeC}$ group (Fig. 2a and b). In the result of scratching behavior test, scratching frequency in PHMW and DHMW was significantly lower than $\mathrm{NeC}$ group in the 2nd week of treatment ( $p<0.01$, respectively) (Fig. 3a). In parallel, the scratching frequency in PHMW was significantly decreased compared to $\mathrm{NeC}$ group in the 4th week $(p<0.05)$ (Fig. 3b). However, there was no significant difference between eczematous skin lesions.

\section{HMW bathing decreases serum IgE level in hairless mice with DNCB-induced AD-like inflammation}

$\mathrm{AD}$ in hairless mice is known to be frequently mediated by IgE. Thus, to further investigate whether bathing in PHMW and DHMW on DNCB-induced hairless mice, retro-orbital bleeding samples were taken on the last day of the 4th week of treatment. Our data revealed that DHMW group was significantly reduced in serum IgE level compared with $\mathrm{NeC}$ group $(p<0.05)$ (Fig. 4). In parallel, the PHMW group also had a lower serum IgE level than the $\mathrm{NeC}$ and $\mathrm{PC}$ groups although there was not significance (Fig. 4).
HMW bathing effects on inflammatory cytokines in hairless mice with DNCB-induced AD-like inflammation Imbalance of cytokines network has been found in $\mathrm{AD}$. Thus, we examined the effect of PHMW and DHMW bathing on serum cytokine profiles in DNCB-induced hairless mice. We found that IL-1 $\beta$ was significantly inhibited by bathing in PHMW $(p<0.05)$ and DHMW $(p<0.001)$ compared to the $\mathrm{NeC}$ group (Fig. 5a). In line, PHMW and DHMW groups showed significantly low level of TNF- $\alpha$ compared to $\mathrm{NeC}$ group $(p<0.001$, respectively) and PC group ( $p<0.01$ and $p<0.001$ ) (Fig. 5b). Of note, the level of IL-13 was significantly low in DHMW group compared to $\mathrm{NeC}$ group $(p<0.01)$ (Fig. $5 \mathrm{c})$.

\section{HMW bathing effects on redox balance in hairless mice with DNCB-induced AD-like inflammation}

To evaluate the effect of PHMW and DHMW bathing on DNCB induced oxidative stress, we examined the effect of PHMW and DHMW on serum redox marker profiles (ROS, MDA, and GPx) in DNCB-induced hairless mice. We found that, total ROS level was significantly decreased in DHMW group compared to the $\mathrm{NeC}$ group $(p<0.05)$ (Fig. 6a). Consistently, serum MDA level was significantly low in PHMW group comapared to $\mathrm{NeC}$ group $(p<0.05)$ (Fig. 6b). Additionally, GPx activity was significantly increased in PHMW group compared to $\mathrm{NeC}, \mathrm{PC}$ and DHMW groups $(p<0.05$, respectively) (Fig. 6c).

\section{Discussion}

Our study investigated balneotherapeutic effects of HMW on DNCB-induced AD-like inflammation in hairless mice via immunomodulation and redox balance. Several in vivo and clinical investigations have reported the positive therapeutic effect of mineral baths on several skin diseases

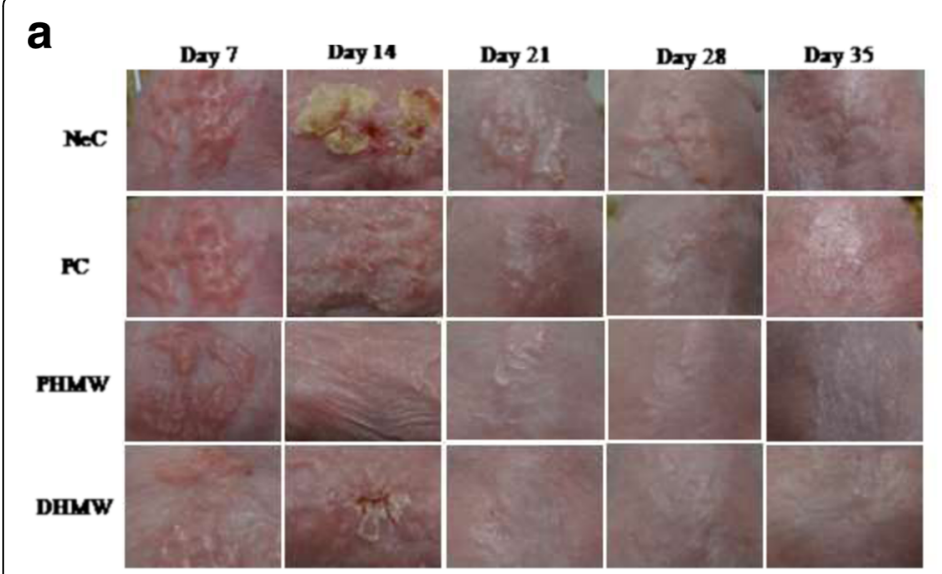

b

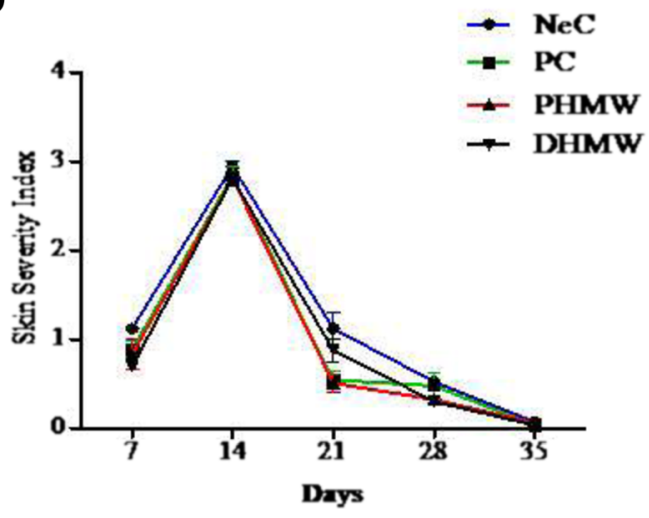

Fig. 2 Bathing effects of HMW on clinical skin severity in DNCB -induced hairless mice. a The dorsal skin of mice were sensitized by DNCB and treated with experimental materials; photographs of skin lesions from each group of mice were taken every week; $\mathbf{b}$ The clinical dermatitis scores of DNCB-treated mice were evaluated weekly from 7 to 35 day. Animal groups are represented as Negative control (NeC), Positive control (PC), $100 \%$ pure high concentration mineral water (PHMW), 10\% diluted high concentration mineral water (DHMW), $n=10$ respectively 

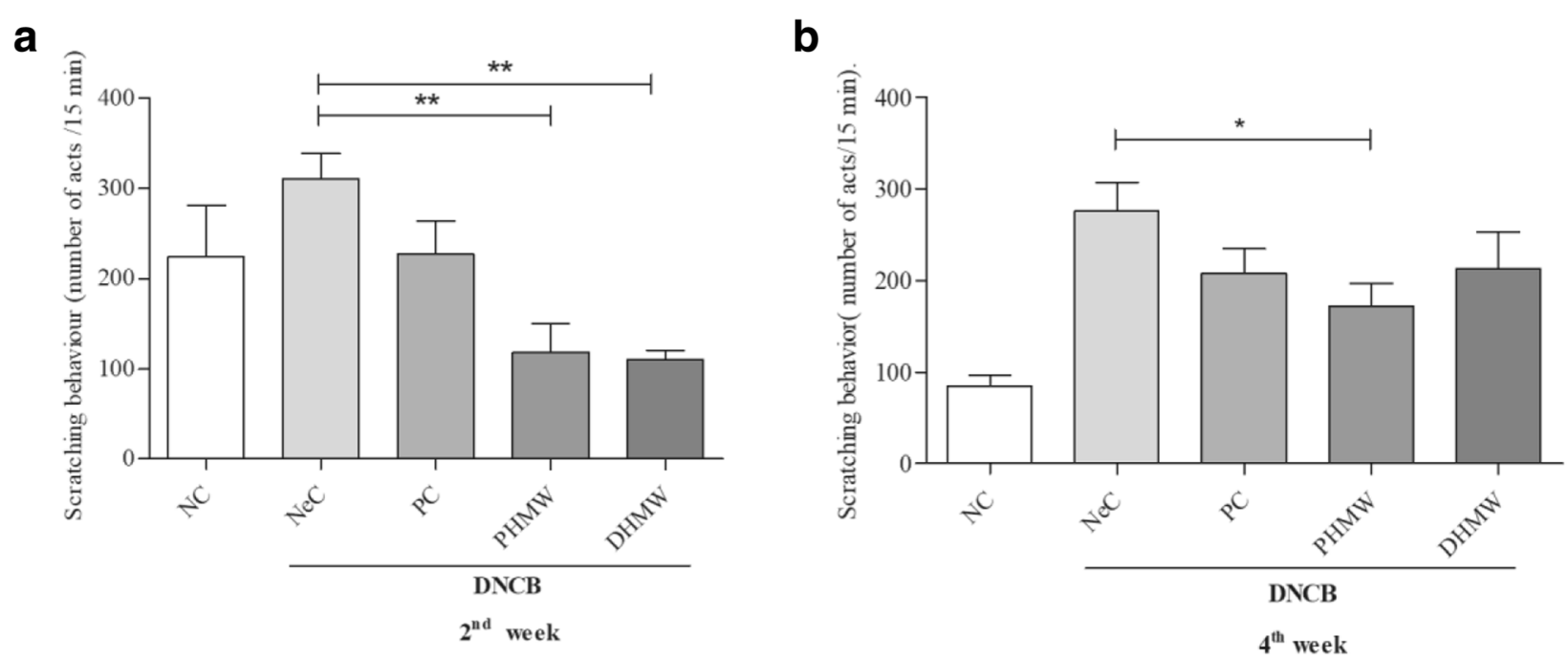

Fig. 3 Bathing effects of HMW on scratching behavior during 2nd (a) and 4th (b) weeks in DNCB-induced hairless mice. Scratching frequency was counted for 15 min in triplicate observation after DNCB-induction in each group. Significant difference was analyzed with ANOVA Tukey's test, ${ }^{*} p<0.05$ and ${ }^{* *} p<0.01$

including $\mathrm{AD}$ through its chemical (mineral components) and mechanical effects [21-23]. Cumulative evidence showed that mineral components such as sulphur [12], manganese [13], magnesium [14] and bicarbonates present in spring water exerted beneficial effects on skin disorders such as AD [24]. Studies reported that mineral water rich in sulphur may be absorbed through the skin, exerting beneficial vasodilation, immunomodulatory, anti-inflammatory, keratoplasty, and anti-pruritic effects [25-27]. Inoue et al. reported that balneotherapeutic effect of spring water is useful for controlling skin symptoms of acute exacerbations of refractory cases of $\mathrm{AD}$ [13]. In line with these, our study showed HMW (PHMW and DHMW) enriched in high complex minerals (magnesium, calcium, chlorine, manganese, sulphur and strontium ions) was effective against DNCB-induced AD like inflammation in hairless mice (Table 1). Further, this was evidenced in our studies via

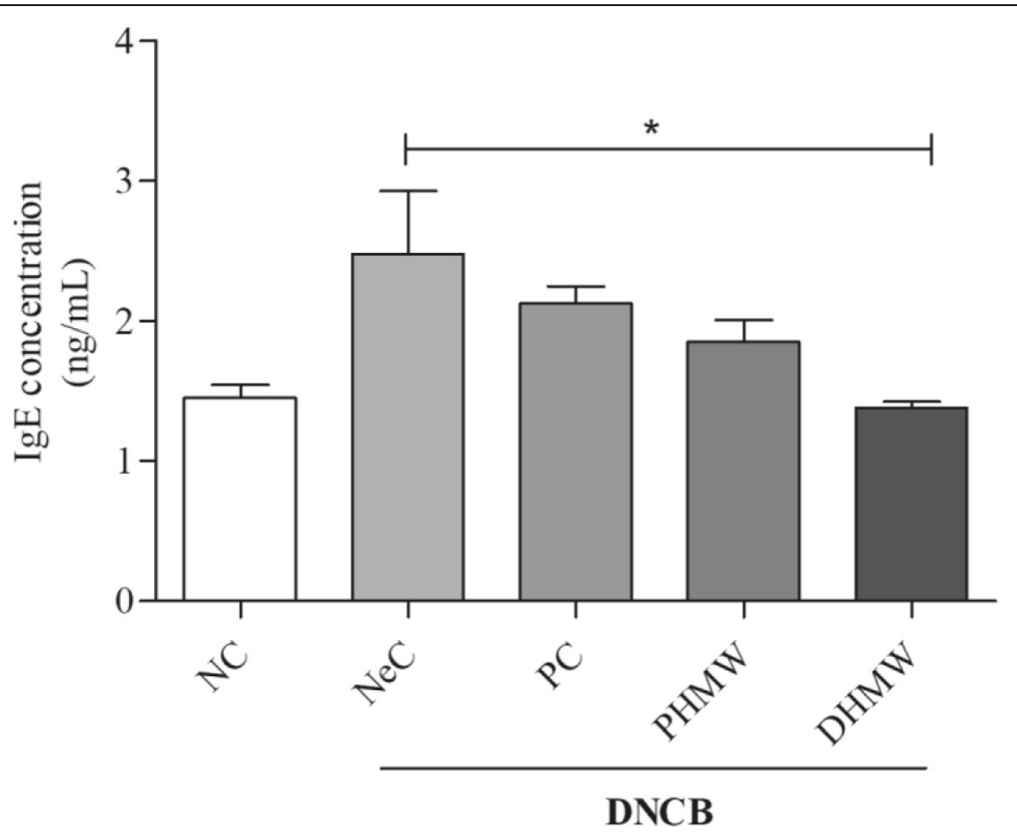

Fig. 4 Bathing effects of HMW on serum IgE level in DNCB-induced hairless mice.The level of serum IgE was measured by ELISA. Animal groups are represented as Negative control (NeC), Positive control (PC), 100\% pure high concentration mineral water (PHMW), 10\% diluted high concentration mineral water (DHMW), $n=10$ respectively. Significant difference was analyzed with ANOVA Tukey's test, ${ }^{*} p<0.05$ 

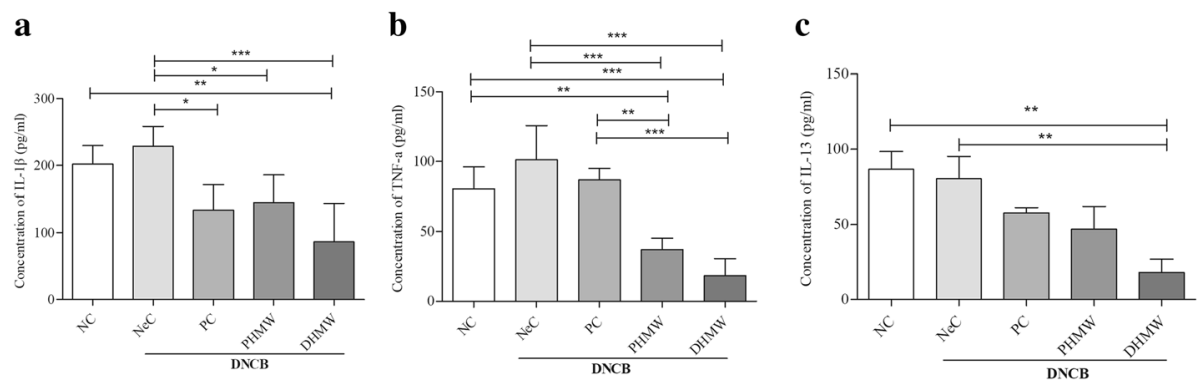

Fig. 5 Bathing effects of HMW in serum inflammatory cytokines levels in DNCB- induced hairless mice. The level of serum cytokines was measured with Bioplex Multiplex Bead array system. a IL-1 $\beta$ cytokine (b) TNF-a cytokine and (c) IL-13 cytokine. Animal groups are represented as Negative control (NeC), Positive control (PC), 100\% pure high concentration mineral water (PHMW), 10\% diluted high concentration mineral water (DHMW),$n=10$ respectively. Significance difference was analyzed with ANOVA Tukey's test, ${ }^{*} p<0.05$, ${ }^{* *} p<0.01$ and ${ }^{* * *} p<0.001$

three ways which are clinicopathological data, immunomodulation and redox balance.

First, we evaluated clinical severity score and scratching frequency of hairless mice. It is well known that $\mathrm{AD}$ is often accompanied by clinical symptoms like erythema, edema, excoriations, and dryness along with severe itching which causes scratching. Unexpectedly, bathing in PHMW and DHMW slightly decreased DNCB-induced skin severity (Fig. 2a and b). More importantly, the scratching frequency of PHMW group was significantly lowered than $\mathrm{NeC}$ group in both the 2nd and 4th week of bathing (Fig. 3a and b). This might be the first note on balneotherapeutic effects of spring water armed with higher levels of complex minerals against $\mathrm{AD}$-like skin diseases. Next, to secure the immunological clue for clinical relief, we measured serum IgE level in DNCB-induced hairless mice because an elevated IgE level as a hallmark of $\mathrm{AD}$ is in proportion to the clinical severity of AD $[28,29]$. Consistent with clinical relief, PHMW and DHMW reduced serum IgE levels in DNCB-induced hairless mice when compared with $\mathrm{NeC}$ group (Fig. 4). Since IgE is a humoral reflection of $\mathrm{Th}_{2}$ immunity, these data might suggest immunomodulation of HMW as a plausible mechanism. In allergic disease, both pro-inflammatory and $\mathrm{Th}_{2}$ cytokines play critical roles in the inflammatory manifestation $[29,30]$. To further confirm immunomodulation in the host, we measured serum cytokines level in the DNCB-induced hairless mice. Cytokine profiling clearly showed a significant reduction of pro-inflammatory cytokines such as IL- $1 \beta$, TNF- $\alpha$, and $\mathrm{Th}_{2}$ cytokine level such as IL-13 in HMW bathed mice compared to the $\mathrm{NeC}$ mice group (Fig. $5 \mathrm{a}-\mathrm{c}$ ). In $\mathrm{AD}$, epidermal cytokines such as IL- $1 \beta$ and TNF- $\alpha$ act as mediators of inflammatory and immune response. In the sensitization and elicitation phase of allergic dermatitis, IL- $1 \beta$ and TNF- $\alpha$ play a pivotal role $[31,32]$. Various chemokines/adhesion molecules which cause the recruitment and proliferating of leukocytes within the skin are produced by TNF- $\alpha$ at the initiation stage of AD. Besides, as cytokine IL-13 is known to be a key stimulator of inflammation and tissue remodeling at sites of $\mathrm{Th}_{2}$ inflammation, elevated IL-13 level has been detected in the skin lesions of AD $[33,34]$. Taken together, inhibition of pro-inflammatory cytokines including IL- $1 \beta$ andTNF- $\alpha$ as well as reduction of the $\mathrm{Th}_{2}$ cytokine IL-13 level might be effective against the overall stages of $\mathrm{AD}[32,33]$. Consistently, this might be supported by bathing effect with sea water that would
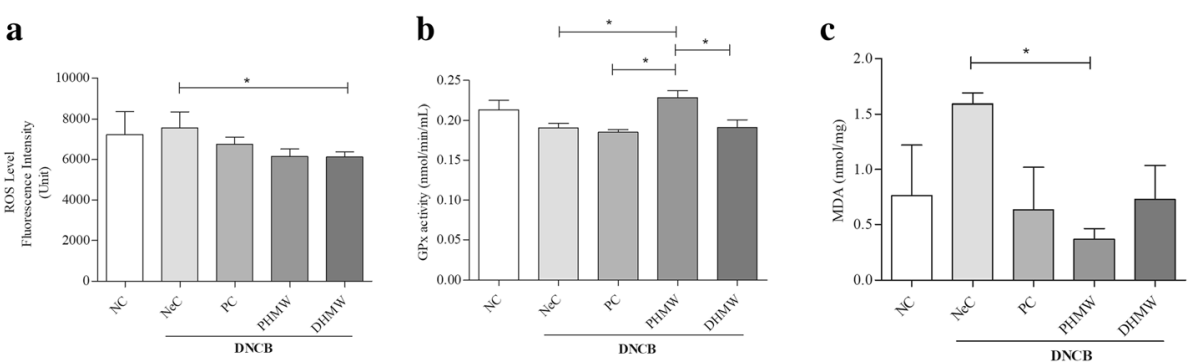

Fig. 6 Bathing effects of HMW on serum redox balance markers in DNCB- induced hairless mice. a ROS by DCFH-DA (b) MDA by thiobarbituric acid reactive substances (TBARS) assay kit (c) GPX activity by GPx assay kit. Animal groups are represented as Negative control (NeC), Positive control (PC), 100\% pure high concentration mineral water (PHMW), 10\% diluted high concentration mineral water (DHMW), $n=10$ respectively. Significant difference was analyzed with ANOVA Tukey's test, ${ }^{*} p<0.05$ 
ameliorate the AD-like inflammation by way of modulating the production of $\mathrm{Th}_{2}$ and pro-inflammatory cytokines in DNCB-induced hairless mice [9].

It is also well known that oxidative stress promotes tissue inflammation through the up regulation of genes that code pro-inflammatory cytokines [35]. Lastly, to explore the linkage of redox imbalance in the pathophysiology of $\mathrm{AD}$, we analyzed different oxidative stress markers. We found that the ROS level of the DHMW group was significantly lower than that of the $\mathrm{NeC}$ group (Fig. 6a). Since ROS is considered as one of the important biomarkers of oxidative stress and act as a secondary messenger that can induce the generation of pro-inflammatory and $\mathrm{Th}_{2}$ cytokines during inflammatory signaling $[35,36]$. Besides this, oxidative stress in AD would be detrimental to lipids, proteins, and DNA. Lipid peroxidation act as an endogenous danger signals that might be responsible for AD pathogenesis, and escalating level of ROS would induce lipid peroxidation [37]. Further, to support this notion, we determined serum MDA level, which is a conventional marker to sense overall lipid peroxidation and oxidative stress. In line, we found significant lower level of MDA in PHMW group as compared to the $\mathrm{NeC}$ group (Fig. 6b). Current studies have identified the potential role of lipid peroxidation in numerous pathological condition such as inflammation [37, 38]. Considering the reduction of oxidative effector, ROS, and MDA, our results importantly suggest that bathing with high mineral water is effective against the oxidative stress in DNCB-induced hairless mice. On the other hand, allergic reactions in the skin with allergens is known to affect the antioxidant defense system such as antioxidant enzymes. Thus to examine the bathing effect of HMW on the antioxidant defense system of the DNCB-induced mice, we measured GPx activity in both treatment and control groups and found that there was the significance enhanced activity of GPx in PHMW group compared to the $\mathrm{NeC}$ and PC groups (Fig. 6c). This might be partly supported by the balneotherapeutic effect of our high mineral rich spring water increased the activity of GPx activity and is, thereby suggesting a protective role in DNCB-induced AD like inflammation in hairless mice. GPx acts as an important peroxide scavenging enzyme thus offering protection from oxidative stress in tissue by maintaining low levels of ROS [38]. Consistent with our results, several studies have already proven that balneotherapy has potent antioxidant effect in various dermatitis $[9,39,40]$. However, the detailed molecular mechanism underlying the antioxidant effects still remains to be elucidated, and the validated proof in another relevant animal model is required. Given these, our redox profiling showed that HMW might stabilize via enhancing the level of endogenous antioxidants as well as reducing the level of oxidative effectors, thus clinically suggesting its potential beneficial effect against skin diseases including allergic AD-like inflammation. However, further studies with specific analyses of immune-redox makers associated with $\mathrm{AD}$ and the relevant signal pathways involved is needed for dissecting the molecular mechanism of balneotherapeutic effect.

\section{Conclusion}

Collectively, our study indicates that bathing with HMW ameliorates DNCB-induced skin inflammation by inhibiting the allergic response (such as serum IgE level and scratching behavior), inflammatory response (such as inflammatory cytokines; IL- $1 \beta$, TNF- $\alpha$, and IL-13) in female skh-1 hairless mice. Besides that, levels of redox balance markers (ROS and MDA) were also significantly inhibited with HMW bathing. Taken together, results importantly imply that bathing with HMW might be a safe alternative, a non-medicinal remedy against AD.

\begin{abstract}
Abbreviations
AD: Atopic dermatitis; ANOVA: One-way analysis of variance; DCFH-DA: 2, 4dichlorodihydrofluorescediacetate; DHMW: 10\% Diluted high mineral spring water; DNCB: 2,4- dinitrochlorobenzene; DW: Distilled water; ELISA: Enzyme linked immunosorbentassay; GPx: Glutathione peroxidase; HMW: High mineral concentration spring water; IACUC: Institutional animal care and use committee; IgE: Immunoglobulin E; IL: Interleukin; MDA: Malondialdehyde; NADPH: Nicotinamide adenine dinucleotide phosphate; NC: Normal control; NeC: Negative control; PC: Positive control; PHMW: 100\% Pure high mineral concentration spring water; ROS: Reactive oxygen species; SA: Staphylococcus aureus; TBARS: Thiobarbituric acid reactive substances; TNF-a: Tumor necrosis factor-alpha
\end{abstract}

\section{Acknowledgements}

The authors acknowledge the support provided by Dr. Easter Joy Sajo during the analyses of data and experiment.

\section{Funding}

This work was supported by the Ministry of Education of the Republic of Korea and the National Research Foundation of Korea (NRF2016S1A5B8925203).

\section{Availability of data and materials}

The data sets supporting the conclusions of this article are included within the article.

\section{Authors' contributions \\ Conceived and designed the experiments: JB, KLL and CSK; Performed the experiments by: JB, AF, JA, FA and RB. Analyzed the data: JB, CSK and AF; Wrote the paper: JB; Revision and feedback of article done: KSS, SKK and KJL. All authors read and approved the final manucript.}

\section{Ethics approval and consent to participate}

The study protocol of the present study was approved by the Institutional Animal Care and Use Committee (IACUC) at Wonju Campus, (Ethical approval no:YWC-160513-1) Yonsei University, Gangwon, Wonju and Republic of Korea.

\section{Consent for publication}

Not applicable.

Competing interests

The authors declare that they have no competing interests. 


\section{Publisher's Note}

Springer Nature remains neutral with regard to jurisdictional claims in published maps and institutional affiliations.

\section{Author details \\ 'Department of Environmental Medical Biology, Wonju College of Medicine, Yonsei University, Wonju, Gangwon 26426, Republic of Korea. ${ }^{2}$ Department of Global Medical Science, Wonju College of Medicine, Yonsei University, Wonju, Gangwon 26426, Republic of Korea. ${ }^{3}$ Department of Microbiology, Wonju College of Medicine, Yonsei University, Wonju, Gangwon 26426, Republic of Korea. ${ }^{4}$ Department of Internal Medicine, Wonju College of Medicine, Yonsei University, Wonju, Gangwon 26426, Republic of Korea. 5 Institute for Poverty Alleviation and International Development (IPAID) Yonsei University, Wonju Campus, Wonju, Gangwon 26493, Republic of Korea.}

\section{Received: 25 May 2017 Accepted: 2 October 2017}

\section{Published online: 13 October 2017}

\section{References}

1. Boguniewicz M, Leung DY. Recent insights into atopic dermatitis and implications formanagement of infectious complications. J Allergy Clin Immunol. 2010;125:4-13.

2. Asher MI, Montefort S, Björkstén B, Lai CK, Strachan DP, Weiland SK, et al. ISAAC phase three study. Worldwide time trends in the prevalence of symptoms of asthma, allergic rhino conjunctivitis, and eczema in childhood. ISAAC phases one and three repeat multicountry cross-sectional surveys. Lancet. 2006;368:733-43.

3. Thomsen SF. Atopic dermatitis: natural history, diagnosis, and treatment ISRN Allergy. 2014;2014:354250. https://doi.org/10.1155/2014_354250.

4. Geha R. Allergy and hypersensitivity. Nature versus nurture in allergy and hypersensitivity. Curr Opin Immunol. 2003;15:603-8.

5. Pariser D. Topical corticosteroids and topical calcineurin inhibitors in the treatment of atopic dermatitis: focus on percutaneous absorption. Am J Ther. 2009:16:264-73.

6. Adams DH, Fueyo AS, Samuel D. From immune suppression to tolerance. Hepatol. 2015:62:S170-85.

7. Routh HB, Bhowmik KR, Parish LC, Witkowski JA. Balneology, mineral water and spas in historical perspective. Clin Dermatol. 1996;14:551-4.

8. Andreassi L, Flori L. Mineral water and spas in Italy. Clin Dermatol. 1996;14:627-32.

9. Kim CG, Kang M, Lee YH, Min WG, Kim YH, Kang SJ, et al. Bathing effects of various seawaters on allergic (atopic) dermatitis-like skin lesions induced by 2,4-dinitrochlorobenzene in hairless mice. Evid Based Complement Altern Med. 2015;2015:179185. https://doi.org/10.1155/2015_179185.

10. Matz H, Orion E, Wolf R. Balneotherapy in dermatology. Dermatol Ther. 2003:16:132-40.

11. Lotti T, Ghersetich I. Le basidelladermocosmetologiatermale. In: Caputo R, Monti M, editors. Manuale di Dermocosmetologia, vol. 1995. Milan: Raffaello Cortina; 1995. p. 751-62.

12. Valitutti $\mathrm{S}$, Costellino F, Musiani P. Effect of sulphurous "thermal water" on $T$ lymphocytes proliferative response. Ann Allergy. 1990;65:463-8.

13. Inoue $T$, Inoue $S$, Kubata K. Bacterial activity of manganese and iodide ions against staphylococcus aureus: a possible treatment for acute atopic dermatitis. Acta Derm Venereol. 1999;79:360-2

14. Denda M, Katagiric C, Hiro T, Maruyama N, Takahashi M. Some magnesium salts and the mixture of magnesium and calcium salts accelerate skin barrier recovery. Arch Dermatol Res. 1999;291:560-3.

15. Takahashi H, Nakazawa M, Takahashi K, Aihara M, Minami M, Hirasawa T, et al. Effects of zinc deficient diet on the development of atopic dermatitislike eruptions in DS-Nh mice. J Dermatol Sci. 2008;50:31-9.

16. Celerier P, Richard A, Litoux $P$, Dreno B. Modulatory effects of selenium and strontium salts on keratinocyte-derived inflammatory cytokines. Arch Dermatol Res. 1995;287:680-2.

17. Olah M, Koncz A, Feher J, Kamanczhey J, Olah C, Nagy G, et al. The effect of balneotherapy on antioxidant, inflammatory, and metabolic indices in patients with cardiovascular risk factors (hypertension and obesity) a randomized, controlled follow-up study. Contemp Clin Trials. 2011:32:793-801.

18. Kubota K, Machida I, Tamura K, Take H, Kurabayashi H, Akiba T, et al. Treatment of refractory cases of atopic dermatitis with acidic hot-spring bathing. Acta Derm Venereol. 1997;77:452-4.
19. Akiyama H, Yamasaki O, Tada J, Kubota K, Arata J. Antimicrobial effects of acidic hot-spring water on Staphylococcusaureus strains isolated from atopic dermatitis patients. J Dermatol Sci. 2000;24:112-8.

20. Kim H, Kim JR, Kang H, Choi J, Yang H, Lee $P$, et al. 7,8,4'Trihydroxyisoflavoneattenuates DNCB-induced atopic dermatitis like symptoms in NC/Nga mice. PLos One. 2014;9(8):e104938. https://doi.org/10. 1371/2014_e104938.

21. Adler-Cohen C, Czarnowicki T, Dreiher J, Ruzicka T, Ingber A, Harari M. Climatotherapy at the Dead Sea: an effective treatment modality for atopic dermatitis with significant positive impact on quality of life. Dermatitis. 2012;23:75-80

22. Merial KM, Mengual X, Guerrero D, Sibaud V. Clinical efficacy of Avène hydrotherapy measured in a large cohort of more than 10,000 atopic or psoriatic patients. J Eur Acad Dermatol Venereol. 2011;25(Suppl 1):30-4. doi: 10.1111/j.1468-3083.2010.03900.x

23. Gambichler T, Küster W, Kreuter A, Altmeyer P, Hoffmann K. Balneophototherapy - combined treatment of psoriasis vulgaris and atopic dermatitis with salt water baths and artificial ultraviolet radiation. J Euro Acad Derma Venereo. 2000;14:425-8.

24. Bacle I, Meges S, Lauze C, Macleod P, Dupuy P. Sensory analysis of four medical spa spring watercontaining various mineral concentrations. Int J Dermatol. 1999:38:784-6.

25. Nasermoddeli A, Kagamimori S. Balneotherapy in medicine: a review. Environ Health Prev Med. 2005:10:171-9.

26. Sukenik S, Buskila D, Neumann L, Kleiner BA, Zimlichman S, Horowitz J, et al Sulphur bath and mud pack treatment for rheumatoid arthritis at the Dead Sea area. Ann Rheum Dis. 1990;49:99-102.

27. Rodrigues L, Ekundi VE, Florenzano J, Cerqueira AR, Soares AG, Schmidt TP, et al. Protective effects of exogenous and endogenous hydrogen sulfide in mast cell-mediated pruritus and cutaneous acute inflammation in mice. Pharma Res. 2017:115:255-66.

28. Boguniewicz M, Schmid-Grendelmeier P, Leung DY, et al. J Allergy Clin Immunol. 2006:118:40-3.

29. Kim SR, Choi HS, Seo HS, Choi YK, Shin YC, Ko SG. Topical application of herbal mixture extract inhibits ovalbumin-or 2, 4-dinitrochlorobenzeneinduced atopic dermatitis. Evid-Based Complementary Alter Med. 2012;2012: 545497. https://doi.org/10.1155/2012 545497.

30. Stone SP, Muller SA, Gleich GS. IgE levels in atopic dermatitis. Arch Dermatol. 1973:108:806-11.

31. Enk AH, Katz SI. Early events in the induction phase of contact sensitivity. J Invest Dermatol. 1992;99:39S-41S

32. Larsen CG, Ternowitz T, Larsen FG, Thestrup-Pedersen K. Epidermis and lymphocyte interactions during an allergic patch test reaction. J Invest Dermatol. 1988:90:230-3.

33. Coondoo A. The role of cytokines in the Pathomechanism of cutaneous disorders. Indian J Dermatol. 2012;57:90-6.

34. Homey B, Steinhoff M, Ruzicka T, Leung DY. Cytokines and chemokines orchestrate atopic skin inflammation. J Aller Clini Immuno. 2006:118:178-89.

35. Kannan K, Jain SK. Oxidative stress and apoptosis. Pathophysiology. 2000;7: $153-63$

36. Dormandry TL. Free radical oxidation and antioxidants. Lancet. 1978;311: 647-50.

37. Ramana KV, Srivastava S, Singhal SS. Lipid peroxidation products in human health and disease. Oxidative Med Cell Longev. 2017;2017:162414. https:// doi.org/10.1155/2017_2163285.

38. Odabasoglu F, Cakir A, Suleyman H, Aslan A, Bayir Y, Halici M, et al. Gastroprotective and antioxidant effects of usnic acid on indomethacininduced gastric ulcer in rats. J Ethnopharmaco. 2006;103:59-65.

39. Yoon YS, Sajo ME, Ignacio RM, Kim SK, Kim CS, Lee KJ. Positive effects of hydrogen water on 2, 4-dinitrochlorobenzene-induced atopic dermatitis in NC/Nga mice. Biol Pharm Bull. 2014:37:1480-5.

40. Prandelli C, Parola C, Buizza L, Delbarba A, Marziano M, Salvi V, et al. Sulphurous thermal water increases the release of the anti-inflammatory cytokine IL-10 and modulates antioxidant enzyme activity. Inter J Immunopathol Pharmacol. 2013;26:633-6. 